\title{
Radial Growth Response of Picea crassifolia to Climatic Conditions in a Dryland Forest Ecosystem in Northwest China
}

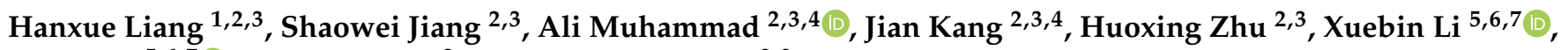 \\ Lin Chen ${ }^{5,6,7}$, Liangjun Zhu ${ }^{8}$ and Jian-Guo Huang ${ }^{2,3, *}$
}

1 Key Laboratory of Ecological Restoration of Loess Plateau, Institute of Loess Plateau, Shanxi University, Taiyuan 030006, China; hansl@sxu.edu.cn

2 Key Laboratory of Vegetation Restoration and Management of Degraded Ecosystems, South China Botanical Garden, Chinese Academy of Sciences, 723 Xingke Road, Tianhe District, Guangzhou 510650, China; shaoweij@scbg.ac.cn (S.J.); muhammadali.eco1@gmail.com (A.M.); kangj@scbg.ac.cn (J.K.); hzhu@scbg.ac.cn (H.Z.)

3 Guangdong Provincial Key Laboratory of Applied Botany, South China Botanical Garden, Chinese Academy of Sciences, 723 Xingke Road, Tianhe District, Guangzhou 510650, China

4 University of Chinese Academy of Sciences, 19(A) Yuquan Road, Shijingshan, District, Beijing 100049, China

5 Key Laboratory of Restoration and Reconstruction of Degraded Ecosystem in Northwest China, Ningxia University, Ministry of Education, Yinchuan 750021, China; lixuebin@nxu.edu.cn (X.L.); chenlin198388@163.com (L.C.)

6 Breeding Base for State Key Laboratory of Land Degradation and Ecological Restoration in Northwest China, Ningxia University, Yinchuan 750021, China

7 College of Ecology and Environment, Ningxia University, Yinchuan 750021, China

8 National Engineering Laboratory for Applied Technology of Forestry \& Ecology in South China, College of

check for

updates

Citation: Liang, H.; Jiang, S.; Muhammad, A.; Kang, J.; Zhu, H.; Li, X.; Chen, L.; Zhu, L.; Huang, J.-G. Radial Growth Response of Picea crassifolia to Climatic Conditions in a Dryland Forest Ecosystem in Northwest China. Forests 2021, 12, 1382. https://doi.org/10.3390/ f12101382

Academic Editor: Ilona Mészáros

Received: 16 September 2021

Accepted: 5 October 2021

Published: 11 October 2021

Publisher's Note: MDPI stays neutral with regard to jurisdictional claims in published maps and institutional affiliations.

Copyright: (c) 2021 by the authors. Licensee MDPI, Basel, Switzerland. This article is an open access article distributed under the terms and conditions of the Creative Commons Attribution (CC BY) license (https:// creativecommons.org/licenses/by/ $4.0 /)$. Life Science and Technology, Central South University of Forestry and Technology, Changsha 410004, China; liangjun_zhu@126.com

* Correspondence: huangig@scbg.ac.cn

Abstract: As an important barrier against desert invasion in Northwest China, Helan Mountains (HL), Luoshan Mountains (LS) and their natural forests have an extremely important ecological status. It is of great significance to study the relationship between forest growth and climate in this region under the background of global change. At present, relevant research mostly focuses on the Chinese pine (Pinus tabulaeformis Carr.), and little is known about how Qinghai spruce (Picea crassifolia Kom.) responds to climate change. To investigate the potential relationships between radial growth of $P$. crassifolia and climatic conditions in Ningxia, China, we collected tree-ring samples from $P$. crassifolia growing in the HL and LS and then established the standard tree-ring width chronologies for the two sites. Correlation analysis together with multivariate linear regression and relative contribution analyses were used, and results showed that radial growth in the HL was determined by the precipitation in the previous September, by the standardized evapotranspiration index (SPEI) in the current March and June, and by the maximum air temperature in the current September. The maximum air temperature in the current September contributed the most (0.348) to the radial growth in the HL. In the LS, radial growth was determined by the precipitation in the previous September and in the current March and by the minimum air temperature in the current July. The factor that made the most contribution was the precipitation in the current March (0.489). Our results suggested that in the wetting and warming future, growth of $P$. crassifolia in the HL will increase while that in the LS needs further investigation. Our results also provide a basis for predicting how P. crassifolia in northwest China will grow under the background of future climate change and provide a reference for formulating relevant management measures to achieve ecological protection and sustainable development policies.

Keywords: tree-ring; growth-climate relationship; Helan Mountains; Luoshan Mountains; Ningxia Hui Autonomous Region 


\section{Introduction}

Being vital massive carbon pools in the terrestrial ecosystems, forests are facing severe challenges posed by global warming. For instance, global forest decline and even forest mortality have been observed in the past decades, and these phenomena were found to have been caused by competition [1,2], megadroughts [3], frequent spring frost [4-6], abnormal warming $[7,8]$, and even insect outbreaks $[9,10]$. Meanwhile, forest growth enhanced by rising air temperature has been reported in some alpine regions and in high-latitude regions [11-14], indicating that global warming strongly influences carbon storage in forests. In predicting the potential carbon storage of forest ecosystems, understanding how forests responded to climatic changes in the past is of paramount importance. However, given the prevailing complex conditions in forest stands, along with the spatial heterogeneity of global warming, recent studies on forest growth-climate relationships remain insufficiently clear to help in comprehensively predicting the future of forests.

Northwest China is an arid and rainless region. Its forest covers mostly consist of coniferous species and are mainly distributed in mountainous areas. The climate in this region has been getting warmer and wetter since the 1980s [15]. Under this background, how forests in northwest China respond to climate must be studied in order to predict their growth pattern. Many studies have already investigated the relationship between forest growth and climate. For example, Wang et al. [16] found that Schrenk spruce (Picea schrenkiana Fisch. et Mey.) radial growth was mainly limited by precipitation in the central Tianshan Mountains, especially at low altitude. Qin et al. [17] also studied the P. schrenkiana in the north Tianshan Mountains and concluded that the depth of snow cover mainly limited its radial growth. Jiang et al. [12] studied the radial growth of larch (Larix sibirica Ledeb.) growing in the southern slope of the Altai Mountain. They found that the low-elevation forest was affected by precipitation, whereas the high-elevation forest was affected by air temperature. Furthermore, they predicted that with the increasing degree of warming and wetting, the growth of low-elevation trees will accelerate, whereas that of high-elevation trees will be limited by continuous warming. Wang et al. [18] monitored the daily dynamics of Qilian juniper (Sabina przewalskii Kom.) along three altitudinal gradients in the central Qilian Mountains, and they found that growth at all altitudes was positively correlated with precipitation and was negatively correlated with daily maximum air temperature during the entire growing season. However, Gao et al. [19] found that the tree rings of $S$. przewalskii in the Qilian Mountains were limited by cold winter and drought in early spring. Besides, they found that growth of Qinghai spruce (Picea crassifolia Kom.) growing in the lower elevation of the Qianlian Mountains was mainly correlated with moisture conditions in the previous late summer (July-August) and with air temperature in the current March, whereas in the upper tree line, it was limited by air temperature in the previous August and by precipitation in December [20]. Overall, although numerous relevant studies have already been completed, the results are inconsistent and heavily depend on the investigated tree species and forest stands. Thus, more relevant studies are needed.

The Ningxia Hui Autonomous Region is located in northwest China, on the southeastern edge of the Tengger Desert [21]. Three massive national nature reserves can be found in this territory: Helan Mountains (abbreviated as HL), Luoshan Mountains (abbreviated as LS), and Liupanshan Mountains. These mountains and their vegetation have played an important role in preventing the invasion of the Tengger Desert and in protecting the agricultural production and in the ecological safety of the North China Plain and the Loess Plateau, making Ningxia a crucial region with vital research significance. However, the existing research on the relationship between forest growth and climate in this area has mostly focused on Chinese pine (Pinus tabulaeformis Carr.). For example, Liu et al. [22] found that the January-July precipitation explained the greatest variance in radial growth in P. tabulaeformis growing in the south-central HL. Meanwhile, Cai et al. [23] found that the air temperature in January-August is the dominant factor that influences radial growth in P. tabulaeformis growing in the eastern and western HL. Gao et al. [24] found that moisture 
positively affects the dynamics of stem radial increment (SRI) of $P$. tabulaeformis. Wang et al. [25] concluded that in the LS, P. tabulaeformis was mainly positively influenced by spring and annual total precipitation.

Studies on the growth-climate relationships in P. crassifolia have rarely been reported, severely hampering our understanding of the factors limiting the growth of $P$. crassifolia and restricting our assessment of its growth trends and carbon sequestration potential under the background of climate change. In this study, we used the dendrochronological method to elucidate the P. crassifolia-climate relationship in the HL and LS, where natural P. crassifolia forest covers in Ningxia are found. Our hypothesis is that moisture conditions during the growth season determine the radial growth of $P$. crassifolia.

\section{Methods}

\subsection{Study Area}

Ningxia is located in northwestern China (Figure 1, Table 1), and it receives a temperate continental arid and semi-arid climate. Given that it is located in the fringe zone of the region receiving the monsoon, it is extremely sensitive to global climate changes. The natural forests in Ningxia are mainly distributed in the HL in the north and in the LS in the central region. Of the two, the HL demarcates the region receiving $200 \mathrm{~mm}$ rainfall, as well as demarcates the monsoon and non-monsoon regions. Thus, the ecological status of this region is extremely important. The HL consists mainly of $P$. tabulaeformis and P. crassifolia forests. In the low altitude, a small patch of mixed forest consisting of coniferous (P. tabulaeformis) and broad-leaved species (Birch, Betula platyphylla Suk.) is found. Forests in the LS are similar to those in the HL and are dominated by pure P. tabulaeformis and P. crassifolia forests.

Table 1. Site information and statistical parameters in the common period analysis (1950-2018).

\begin{tabular}{cccccccccc}
\hline \multicolumn{9}{c}{ Site Information } & \multicolumn{3}{c}{ Common Period Analysis } \\
\hline Site & Lat. (E) & Lon. (N) & Ele. (m) & Trees/Cores & Time Span & AR1 & Rbar & EPS & SNR \\
\hline HL1 & $38^{\circ} 46^{\prime} 56^{\prime \prime}$ & $105^{\circ} 54^{\prime} 06^{\prime \prime}$ & 2608 & $13 / 23$ & $1860-2018$ & 0.428 & 0.688 & 0.972 & 34.648 \\
HL2 & $38^{\circ} 46^{\prime} 26^{\prime \prime}$ & $105^{\circ} 54^{\prime} 07^{\prime \prime}$ & 2660 & $9 / 18$ & $1917-2018$ & 0.781 & 0.735 & 0.984 & 31.1397 \\
HL3 & $38^{\circ} 46^{\prime} 25^{\prime \prime}$ & $105^{\circ} 54^{\prime} 03^{\prime \prime}$ & 2920 & $18 / 32$ & $1885-2018$ & 0.638 & 0.737 & 0.969 & 62.66 \\
LS1 & $37^{\circ} 18^{\prime} 00^{\prime \prime}$ & $106^{\circ} 16^{\prime} 02^{\prime \prime}$ & 2479 & $16 / 29$ & $1944-2018$ & 0.710 & 0.595 & 0.96 & 23.82 \\
LS2 & $37^{\circ} 19^{\prime} 48^{\prime \prime}$ & $106^{\circ} 16^{\prime} 02^{\prime \prime}$ & 2497 & $20 / 40$ & $1894-2018$ & 0.600 & 0.54 & 0.966 & 28.237 \\
HL & - & - & - & $40 / 73$ & $1860-2018$ & 0.633 & 0.66 & 0.989 & 93.085 \\
LS & - & - & - & $36 / 69$ & $1894-2018$ & 0.646 & 0.509 & 0.976 & 41.086 \\
\hline
\end{tabular}

Lat., latitude; Lon., longitude; Ele., elevation above sea level; AR1, first-order autocorrelation.

\subsection{Meteorological Data}

The weather station closest to the sampling site in the HL is the Yinchuan Station $\left(106^{\circ} 12^{\prime} 36^{\prime \prime} \mathrm{E}, 38^{\circ} 20^{\prime} 24^{\prime \prime} \mathrm{N}\right.$, Ele. $1106.2 \mathrm{~m}$ a.s.l.), where data recording began in 1953 and where not a single year was missed. During the period 1953-2018, the annual average air temperature was $9.2{ }^{\circ} \mathrm{C}$, the annual average maximum/minimum air temperature was $16.0^{\circ} \mathrm{C} / 3.3^{\circ} \mathrm{C}$, and the total annual rainfall was $195.1 \mathrm{~mm}$. The highest and lowest monthly average air temperatures were recorded in July and January at 23.8 and $-7.9^{\circ} \mathrm{C}$, respectively. Rainfall was concentrated in the summer (July-September), accounting for $60.0 \%$ of the annual precipitation (Figure 2a). The Zhongning Meteorological Station $\left(105^{\circ} 24^{\prime} 36^{\prime \prime} \mathrm{E}, 37^{\circ} 17^{\prime} 24^{\prime \prime} \mathrm{N}\right.$, Ele. $1183.4 \mathrm{~m}$ a.s.l.), which is the station closest to the sampling site in the LS, began recording in 1955. During the period 1955-2018, the average annual air temperature was $9.7^{\circ} \mathrm{C}$, the annual average maximum/minimum air temperature was $17.0^{\circ} \mathrm{C} / 3.7^{\circ} \mathrm{C}$, and the total annual rainfall was $208.1 \mathrm{~mm}$. The highest and lowest monthly average air temperatures were observed in July and January at 23.8 and $-6.8^{\circ} \mathrm{C}$, respectively. Rainfall was concentrated in July-September, accounting for $60.3 \%$ of the annual precipitation (Figure 2 b). 


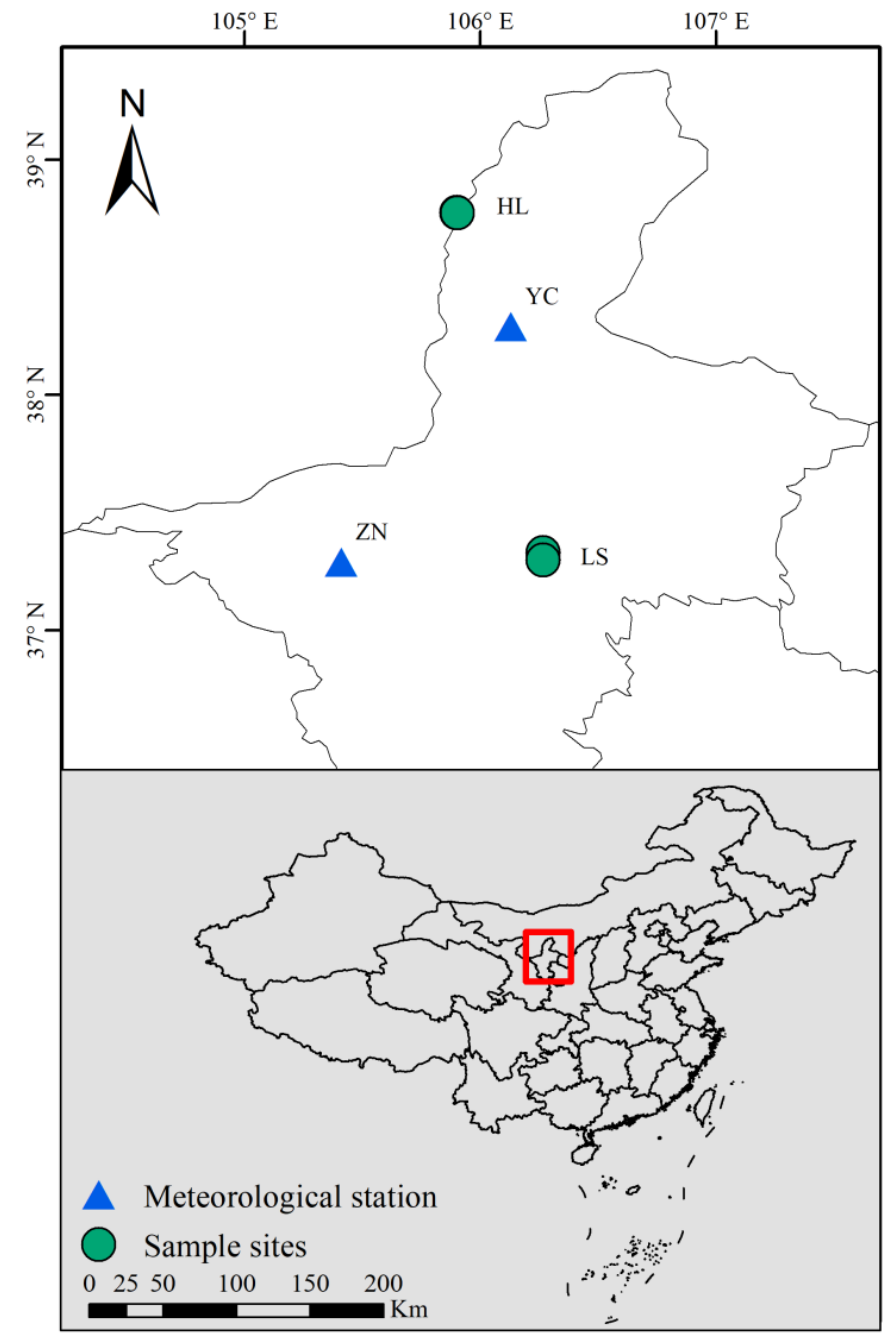

Figure 1. Sampling sites and location of the meteorological stations.

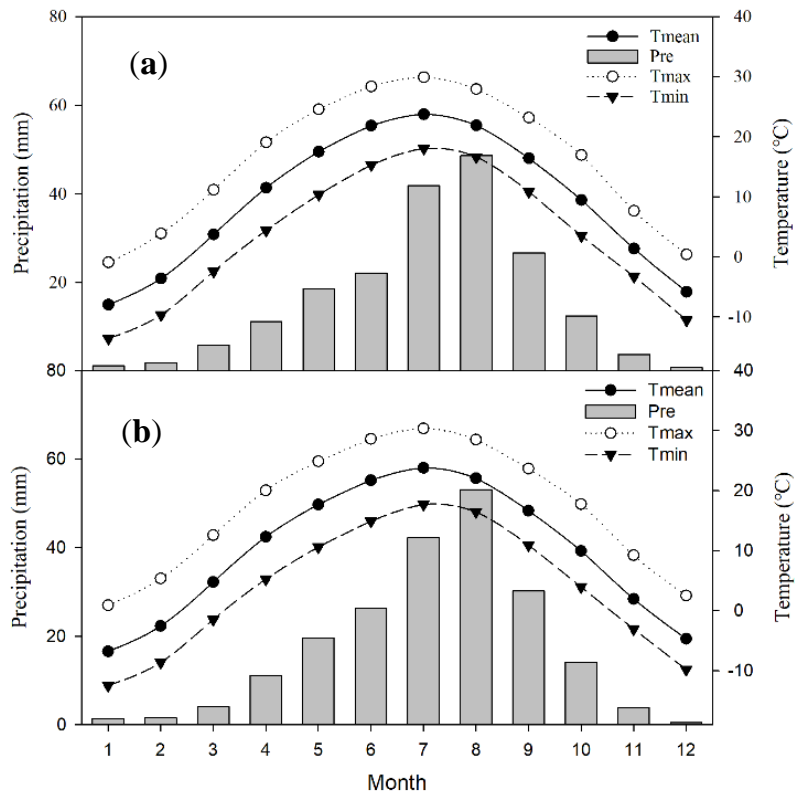

Figure 2. Multi-year (1953-2018) average climatic conditions in the Helan Mountains (a) and Luoshan Mountains (b). 
The moisture conditions were determined from the monthly standardized evapotranspiration index (SPEI), which was calculated by the SPEI package in R [26]. The absolute values of multi-year average SPEI are small, indicating that the moisture conditions in both HL and LS are normal [27]. Relatively speaking, it is slightly drier in the LS than in the HL (Figure 3).

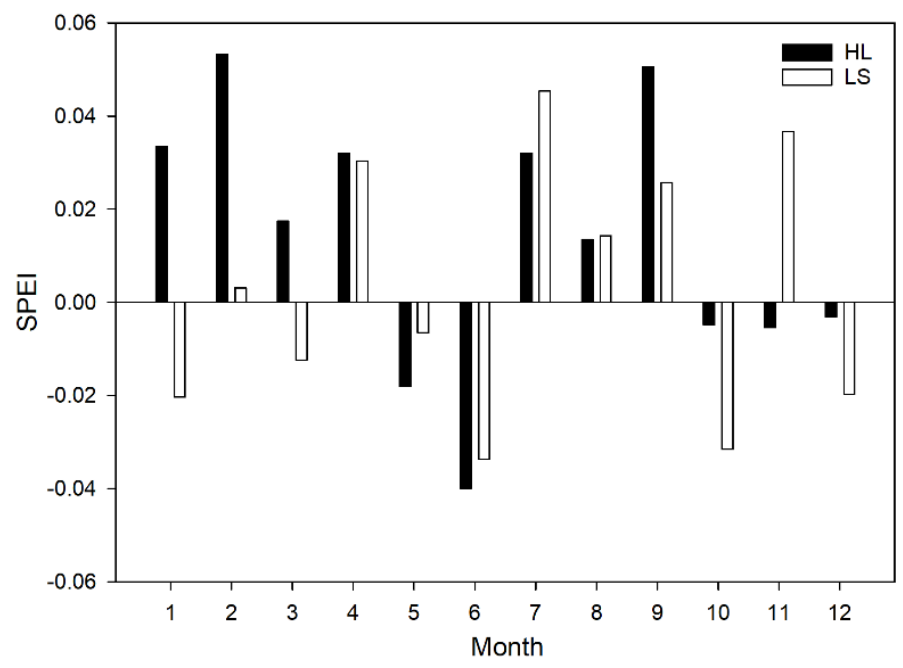

Figure 3. Multi-year (1953-2018) SPEI of the Helan Mountains (HL) and Luoshan Mountains (LS).

\subsection{Tree-Ring Data}

Sampling of P. crassifolia was performed in August of 2018. Pure spruce forests without evidence of human interference were selected as sampling sites. Three and two sampling sites in the HL and LS were selected, respectively (Figure 1 and Table 1). In each site, treering cores with an inner diameter of $5.12 \mathrm{~mm}$ were extracted using an increment borer at breast height from at least 10 individual spruce trees without obvious scars and pests (two cores are usually obtained from each tree). In the laboratory, the tree ring cores were first glued with latex to a wooden support. After the latex had dried, the cores were polished with 120-600 mesh sandpapers. When the xylem cells were clearly visible, visual crossdating was conducted using the skeleton method. Then, the tree-ring widths of each core were measured with Lintab 6 (Frank Rinntech, Heidelberg, German). A total of 73 cores obtained from 40 trees sampled in the HL and 69 cores obtained from 36 trees sampled in the LS were well cross-dated. The quality of the cross-dating results was checked with the COFECHA software [28]. Then, a cubic spline with a 50\% frequency-response cutoff equal to 32 years was used to remove the age-related growth trend, and the double-weighted average method was used to establish the tree-ring width standard chronology for each site. The above steps were performed using the ARSTAN software [29].

Pearson correlation coefficients between the obtained standard chronologies were calculated. It was found that the correlation coefficients among the three site-specific chronologies in the HL were all higher than $0.8(p<0.001)$, and the correlation coefficient between the two chronologies in the LS was $0.76(p<0.001)$ (Appendix A, Table A1). Therefore, we mixed the cores obtained from the HL and from the LS separately and built the region-specific tree-ring width chronologies using the above method for subsequent analysis. A common period analysis of the period 1950-2018 was conducted, and mean interseries correlation coefficients (Rbar), expressed population signal (EPS), and signal-to-noise ratio (SNR) were calculated to evaluate the quality of all the chronologies. Subsample signal strength (SSS), with 0.85 as the threshold, was used to truncate the chronologies [30,31].

\subsection{Data Analysis}

The relationships between region-specific tree-ring width chronologies and climate were determined through correlation analysis based on bootstrapping 1000 times, which 
was conducted with Dendroclim2002 [32]. As study of P. tabulaeformis in this area indicated that the growing season run from May to September [24], climate data were selected from previous September to the current October. The climatic factors involved in the analysis included monthly mean air temperature (Tmean), monthly mean maximum air temperature (Tmax), monthly mean minimum air temperature (Tmin), monthly precipitation (Pre), and SPEI. Then, the stepwise regression method was used to establish the final multivariate linear equation to fit the tree-ring width chronologies. Finally, the contribution of each climate factor to the growth of the spruce forests was analyzed using the relaimpo package in $\mathrm{R}$ [33].

\section{Results}

\subsection{Statistical Parameters of the Chronologies}

The longest series consisted of data from 1860 to 2018 obtained in the HL. The high EPS and SNR values in the regional chronology for the HL during the period 1950-2018 indicated that the chronology contains a high common signal, which may indicate the growth pattern of spruce in the HL. The parameter values for the regional chronology for the LS are relatively lower than those for the HL, but they can also describe the growth of spruce in the LS (Table 1). The correlation coefficient between the two chronologies from 1950 to 2018 is 0.347 ( $p<0.01$ ). The beginning years during which SSS > 0.85 in the regional chronologies for the HL and LS are 1924 and 1955, respectively (Figure 4).

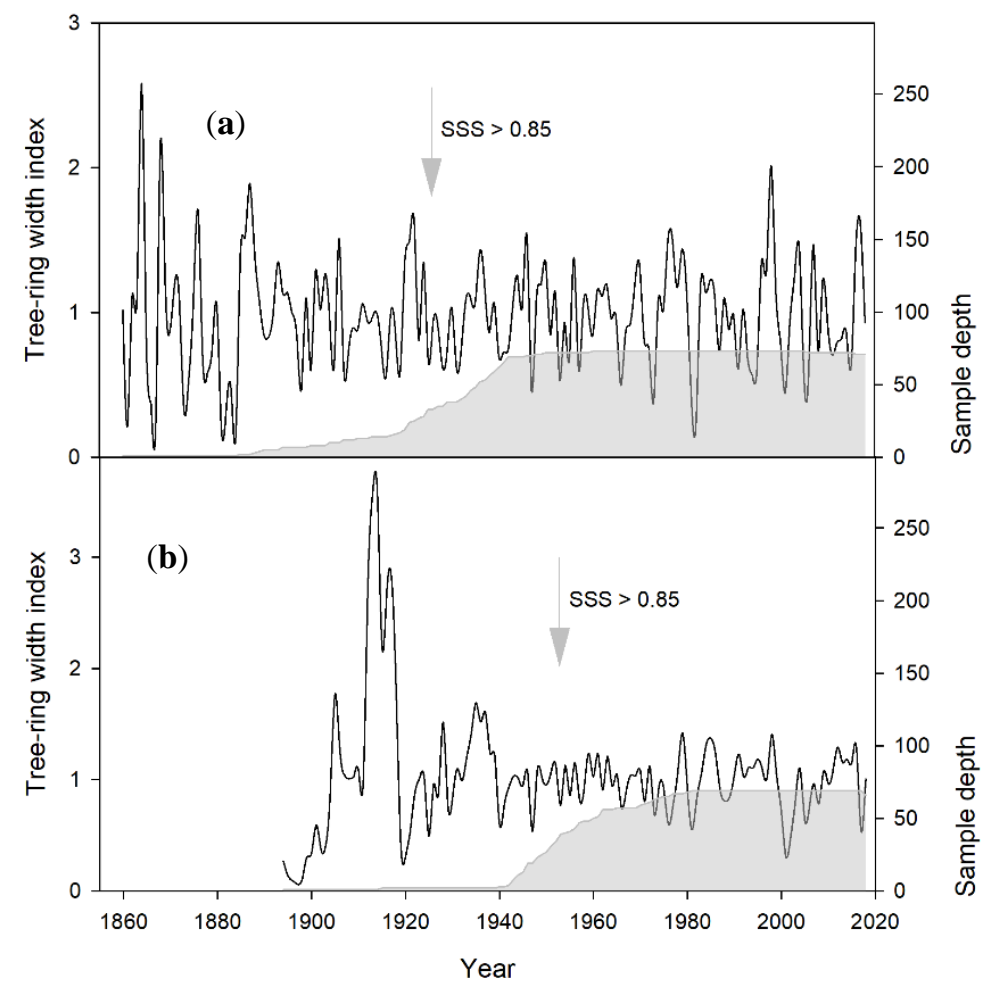

Figure 4. Regional chronologies in Helan Mountains (a) and Luoshan Mountains (b). Grey arrows indicate the beginning year wherein SSS $>0.85$.

\subsection{Growth-Climate Relationship}

Correlation coefficients showed that the precipitation and SPEI in the previous September and in the current March and June exerted significant positive effects on radial growth in the HL (Figure 5). By contrast, the precipitation and SPEI in the current September exerted a significant negative effect on growth in the HL. The monthly mean maximum air temperature in the current March was negatively correlated with the radial growth in HL, whereas the maximum air temperatures in the previous October and in the current September were positively correlated with the radial growth in the HL. The mean air 
temperature and minimum air temperature had no significant correlation with the radial growth of spruce in the HL.

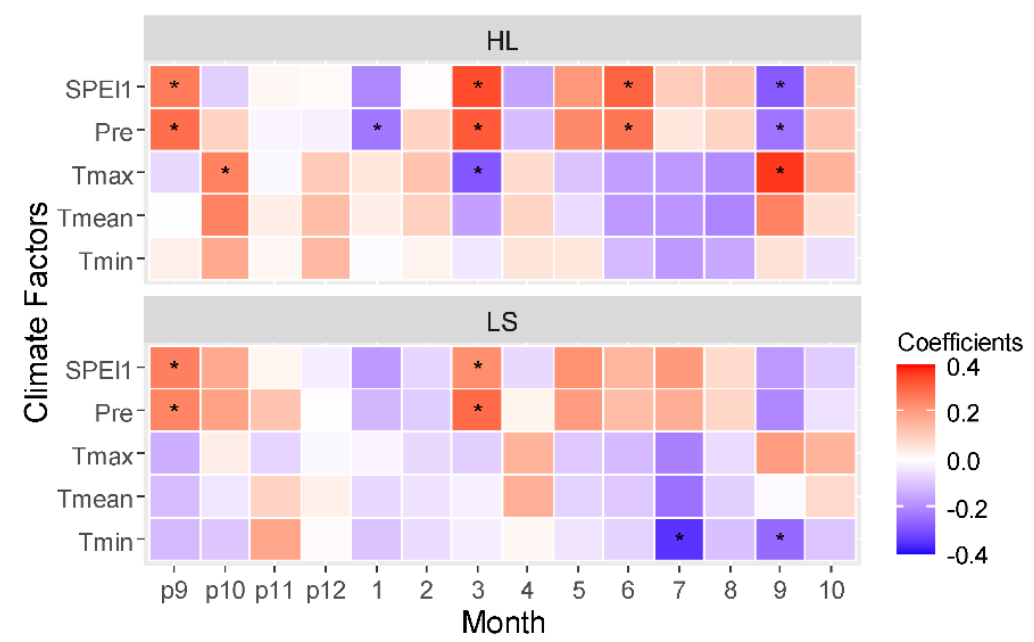

Figure 5. Correlation coefficients between regional chronologies and climate factors. * indicates the significant at level of $0.05 ; p$ indicates the months of previous year.

The correlation coefficients between radial growth in the LS and climate indicate that growth is positively affected by the rainfall conditions and SPEI values in the previous September and in the current March, a pattern that is similar to that in the HL (Figure 5). However, the precipitation and SPEI in the current June have no significant effects on the growth in the LS. Besides, the dominant relationships between air temperature and growth in the LS are demonstrated by the negative effects of the minimum air temperature in the current July and September on radial growth; these findings are totally different from that obtained in the HL.

\subsection{Multiple Regression and Relative Contributions}

The climate factors described in Section 3.2 were used to fit the chronologies. The results of the stepwise regression showed that growth in the HL was mainly determined by the precipitation in the previous September, by the SPEI in the current March and June, and by the maximum air temperature in the current September. All of these variables explain 0.330 of the total variance in the growth in the $\mathrm{HL}(\mathrm{F}=7.38, p<0.0001)$. The corresponding relative contributions of the above four factors are $0.178,0.255,0.219$, and 0.348 (Figure 6a).

The growth in the LS was mainly fitted by the rainfall conditions in the previous September, by the rainfall conditions in the current March, and by the minimum air temperature in the current July. All these variables explained 0.153 of the variances in the growth in the LS $(\mathrm{F}=3.56, p=0.019)$. The corresponding relative contributions of the three variables are $0.266,0.489$, and 0.245 (Figure $6 b$ ). 


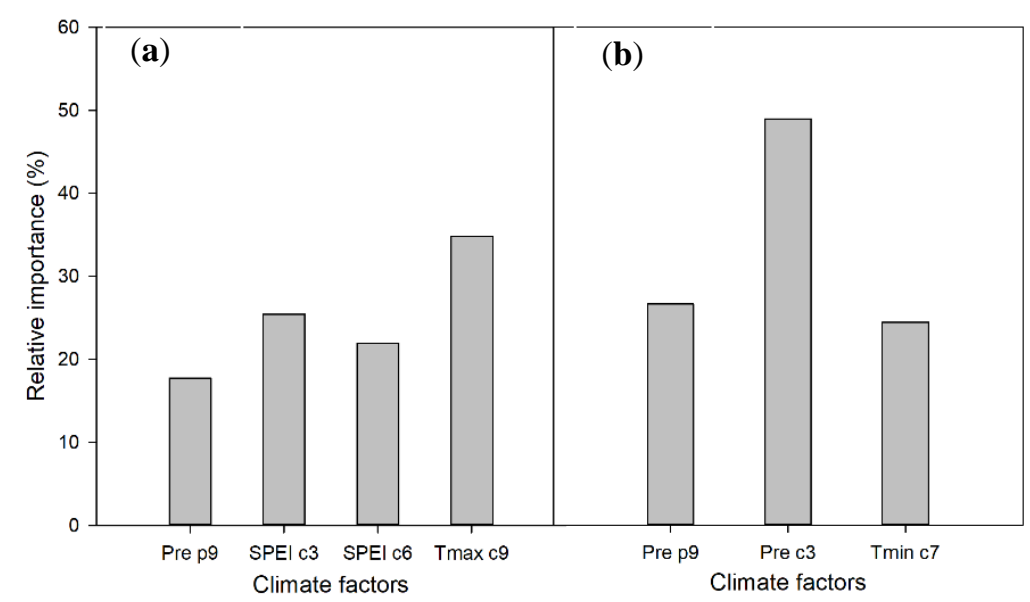

Figure 6. Relative contributions of the predictors in the multi-regression models of radial growth in the Helan Mountains (a) and Luoshan Mountains (b). $p$ indicates the months of previous year; $c$ indicates the months of current year.

\section{Discussion}

The results of the correlation analysis showed that the HL is a precipitation/moisturerestricted area. Previous studies on P. tabulaeformis growing in this area have reached the same conclusion. For example, Liu et al. [34] studied the radial growth of P. tabulaeformis in the northern part of the HL and found that the forest was positively affected by precipitation from May to July. Gao et al. [24] measured the daily radial dynamics of $P$. tabulaeformis with a dendrometer in the middle of the HL in 2016 and 2017, and they found that the summer precipitation was the most important limiting factor. The studies conducted in the Qilian Mountains, another mountain range in northwestern China, also found that the moisture conditions during growth season was the main climatic factor restricting the growth of local P. crassifolia [35]. Our results also showed that the moisture conditions during the previous September significantly promoted the radial growth of trees. The main reason was that higher rainfall conditions at the end of the growing season was conducive for the storage of non-structural organic carbon, which will cause the trees to grow quickly in the following year [36]. This phenomenon can also be confirmed by the high autocorrelation coefficient in all chronologies (Table 1). In addition, the maximum air temperature in the current September had a positive effect on radial growth. Li and Li [37] analyzed the Normalized Difference Vegetation Index (NDVI) of the HL and found that the forest growing season could extend up to September. Then, they simulated the dynamics of xylem formation with the VS. (Vaganov-Shashkin) model and concluded that air temperature was the main limiting factor at the end of the growing season. Shi et al. [38] also simulated the radial growth of $P$. tabulaeformis in the HL using the VS. model and found that the air temperature from September to October had a positive effect on forest growth. It was conjectured that the air temperature drop in the HL began in September, resulting in the shift from moisture to air temperature being the limiting factor. Another finding was that SPEI was relatively more important than precipitation in fitting the chronology in the HL, which is possibly caused by the high evaporation in northwest China during the growing season, especially in the summer [39]. Relative contribution analysis showed that the air temperature in the current September had the greatest positive effect on forest growth. The possible reason is that climate warming leads to a longer growing season. High air temperatures in September will increase the growth rate at the end of the growing season, resulting in wider tree-rings [37]. In this case, under the wetting and warming trend in the northwest China, radial growth of $P$. crassifolia in the HL will be promoted in the near future.

In the LS, the positive effect of precipitation in the previous September and in the current March on the growth of spruce also indicated that it was a water-restricted area, similar to the HL. However, the difference was that in the LS, the minimum air temperature 
in the current July significantly affected forest growth (negative). This finding is similar to that of a study on P. tabulaeformis growing in this area. Wang et al. [25] found that growth of P. tabulaeformis in the LS was significantly positively correlated with spring precipitation and was significantly negatively correlated with air temperature in the summer (especially in July). The possible reason behind these phenomena is that, as demonstrated in several studies, night time is the main period during which plants use organic carbon generated via photosynthesis for cell growth [40-42]. Excessively high air temperatures at night will increase the respiration in trees, intensifying the consumption of organic carbon, ultimately resulting in narrow tree rings. The relative contribution analysis showed that the precipitation in the current March was the dominant limiting factor. This finding indicates that precipitation in the early growing season will most likely determine the growth of trees in this area $[25,43]$. For the positive effects of moisture and negative effects of air temperature, the growth trend of P. crassifolia in the LS still needs further investigation.

The variances explained by the current multiple regression models were lower than those in previous studies on $P$. tabulaeformis growing in our study areas. The main possible reason is that the sampling sites are located in mountainous areas, whereas the nearest weather stations are located in lower elevation, resulting in poor correlation between radial growth and climate records. In addition, the distribution of spruce is higher than that of $P$. tabulaeformis; thus, the meteorological records differed more from the environment of spruce than from that of $P$. tabulaeformis, which may result in the worse response of spruce in terms of growth to the recorded climate than that of P. tabulaeformis. Nevertheless, the correlation analysis and multiple regression results are statistically sound, indicating that the growth-climate relationships and relative contributions of the influencing factors were reliable.

\section{Conclusions}

The dendrochronology method was used to investigate the relationships between the radial growth of $P$. crassifolia and the climate in the HL and in the LS in northwest China. Correlation analysis showed that both sites were positively affected by the moisture conditions in the previous September and at the beginning of the growing season. The difference is that radial growth in the HL was positively affected by the maximum air temperature in the current September, whereas that in LS was negatively affected by the minimum air temperature in the current July. This suggests that there may be differences in growth rates within the growth season, which requires us to explore relevant studies on a finer time scale. In addition, although the results are statistically sound, the variances of spruce growth explained by the climate factors were relatively low. Maybe some other factors dominate the spruce forest growth. Therefore, other factors, like mcroenvironmental information should be considered for future research.

Author Contributions: Conceptualization and methodology, H.L., X.L. and J.-G.H.; performed the experiments, S.J., A.M. and J.K.; manuscript writing, H.L. and L.C.; review and editing, H.Z., X.L, L.Z. and J.-G.H.; supervision, J.-G.H. All authors have read and agreed to the published version of the manuscript.

Funding: This research was funded by the Ningxia Hui Autonomous Region Key Research and Development Project (2018BFG02015) and by the National Natural Science Foundation of China (Grant Nos. 41701047, 41771061).The APC was funded by Open Foundation of Guangdong Provincial Key Laboratory of Applied Botany, South China Botanical Garden, Chinese Academy of Sciences (Grant No. E032041001).

Institutional Review Board Statement: Not applicable.

Informed Consent Statement: Not applicable.

Data Availability Statement: Not applicable.

Acknowledgments: We would like to thank Zhongyou Zhu, Ming Meng, Wenwen Zhang from Ningxia University for their kindly help in field work. We also thank Helan Mountain National 
Nature Reserve, Luoshan National Nature Reserve and Liupanshan National Nature Reserve for their support.

Conflicts of Interest: The authors declare no conflict of interest.

\section{Appendix A}

Table A1. Correlation matrix of site-specific chronologies.

\begin{tabular}{cccccc}
\hline Site & HL1 & HL2 & HL3 & LS1 & LS2 \\
\hline HL1 & \multirow{2}{*}{0.867165} & 0.871953 & 0.242871 & 0.276868 \\
HL2 & & 1 & 0.801229 & 0.272293 & 0.303752 \\
HL3 & & & 1 & 0.277903 & 0.326476 \\
LS1 & & & & 1 & 0.764179 \\
LS2 & & & & & 1 \\
\hline
\end{tabular}

\section{References}

1. Zhang, J.; Huang, S.; He, F. Half-century evidence from western Canada shows forest dynamics are primarily driven by competition followed by climate. Proc. Natl. Acad. Sci. USA 2015, 112, 4009-4014. [CrossRef] [PubMed]

2. Liang, E.; Wang, Y.; Piao, S.; Lu, X.; Camarero, J.J.; Zhu, H.; Zhu, L.; Ellison, A.M.; Ciais, P.; Penuelas, J. Species interactions slow warming-induced upward shifts of treelines on the Tibetan Plateau. Proc. Natl. Acad. Sci. USA 2016, 113, 4380-4385. [CrossRef]

3. Assal, T.J.; Anderson, P.J.; Sibold, J. Spatial and temporal trends of drought effects in a heterogeneous semi-arid forest ecosystem. For. Ecol. Manag. 2016, 365, 137-151. [CrossRef]

4. Silvestro, R.; Rossi, S.; Zhang, S.; Froment, I.; Huang, J.G.; Saracino, A. From phenology to forest management: Ecotypes selection can avoid early or late frosts, but not both. For. Ecol. Manag. 2019, 436, 21-26. [CrossRef]

5. Ma, Q.; Huang, J.-G.; Hänninen, H.; Berninger, F. Divergent trends in the risk of spring frost damage to trees in Europe with recent warming. Glob. Chang. Biol. 2019, 25, 351-360. [CrossRef] [PubMed]

6. Hadad, M.A.; Molina, J.A.; Juñent, F.A.R.; Amoroso, M.M.; Müller, G.; Araneo, D.; Tardif, J.C. Frost record in tree rings linked to atmospheric circulation in northern Patagonia. Palaeogeogr. Palaeoclim. Palaeoecol. 2019, 524, 201-211. [CrossRef]

7. Chen, L.; Huang, J.-G.; Alam, S.A.; Zhai, L.; Dawson, A.; Stadt, K.J.; Comeau, P.G. Drought causes reduced growth of trembling aspen in western Canada. Glob. Chang. Biol. 2017, 23, 2887-2902. [CrossRef]

8. Huang, J.; Tardif, J.C.; Bergeron, Y.; Denneler, B.; Berninger, F.; Girardin, M.P. Radial growth response of four dominant boreal tree species to climate along a latitudinal gradient in the eastern Canadian boreal forest. Glob. Chang. Biol. 2010, 16, 711-731. [CrossRef]

9. Chen, L.; Huang, J.; Dawson, A.; Zhai, L.; Stadt, K.J.; Comeau, P.G.; Whitehouse, C. Contributions of insects and droughts to growth decline of trembling aspen mixed boreal forest of western Canada. Glob. Chang. Biol. 2018, 24, 655-667. [CrossRef] [PubMed]

10. Robson, J.R.M.; Conciatori, F.; Tardif, J.C.; Knowles, K. Tree-ring response of jack pine and scots pine to budworm defoliation in central Canada. For. Ecol. Manag. 2015, 347, 83-95. [CrossRef]

11. Shi, C.; Schneider, L.; Hu, Y.; Shen, M.; Sun, C.; Xia, J.; Forbes, B.C.; Shi, P.; Zhang, Y.; Ciais, P. Warming-induced unprecedented high-elevation forest growth over the monsoonal Tibetan Plateau. Environ. Res. Lett. 2020, 15, 054011. [CrossRef]

12. Jiang, S.; Liang, H.; Zhou, P.; Wang, Z.; Zhu, H.; Kang, J.; Huang, J.-G. Spatial and temporal differences in the response of Larix sibirica to climate change in the central Altai Mountains. Dendrochronologia 2021, 67, 125827. [CrossRef]

13. Qi, Z.; Liu, H.; Wu, X.; Hao, Q. Climate-driven speedup of alpine treeline forest growth in the Tianshan Mountains, Northwestern China. Glob. Chang. Biol. 2015, 21, 816-826. [CrossRef]

14. Jochner, M.; Bugmann, H.; Nötzli, M.; Bigler, C. Tree growth responses to changing temperatures across space and time: A fine-scale analysis at the treeline in the Swiss Alps. Trees 2017, 32, 645-660. [CrossRef]

15. Shi, Y.; Shen, Y.; Kang, E.; Li, D.; Ding, Y.; Zhang, G.; Hu, R. Recent and Future Climate Change in Northwest China. Clim. Chang. 2006, 80, 379-393. [CrossRef]

16. Wang, T.; Ren, H.; Ma, K. Climatic signals in tree ring of Picea schrenkiana along an altitudinal gradient in the central Tianshan Mountains, northwestern China. Trees 2005, 19, 736-742. [CrossRef]

17. Qin, L.; Yuan, Y.; Zhang, R.; Wei, W.; Yu, S.; Fan, Z.; Chen, F.; Zhang, T.; Shang, H. Tree-Ring Response to Snow Cover and Reconstruction of Century annual Maximum Snow Depth for Northern Tianshan Mountains, China. Geochronometria 2016, 43, 9-17. [CrossRef]

18. Wang, Z.; Yang, B.; Deslauriers, A.; Bräuning, A. Intra-annual stem radial increment response of Qilian juniper to temperature and precipitation along an altitudinal gradient in northwestern China. Trees 2015, 29, 25-34. [CrossRef]

19. Gao, L.; Gou, X.; Deng, Y.; Liu, W.; Yang, M.; Zhao, Z. Climate-growth analysis of Qilian juniper across an altitudinal gradient in the central Qilian Mountains, northwest China. Trees 2013, 27, 379-388. [CrossRef] 
20. Gao, L.; Gou, X.; Deng, Y.; Yang, M.; Zhao, Z.; Cao, Z. Dendroclimatic Response of Picea crassifolia along an Altitudinal Gradient in the Eastern Qilian Mountains, Northwest China. Arctic Antarct. Alp. Res. 2013, 45, 491-499. [CrossRef]

21. Li, B.Y.; Pan, B.T.; Cheng, W.M.; Han, J.F.; Qi, D.L.; Zhu, C. Research on geomorphologic regionalization of China. Acta Geogr. Sin. 2013, 68, 291-306, (In Chinese with English abstract).

22. Liu, Y.; Cai, Q.; Shi, J.; Hughes, M.K.; Kutzbach, J.E.; Liu, Z.; Ni, F.; An, Z. Seasonal precipitation in the south-central Helan Mountain region, China, reconstructed from tree-ring width for the past 224 years. Can. J. For. Res. 2005, 35, 2403-2412. [CrossRef]

23. Cai, Q.; Liu, Y. January to August temperature variability since 1776 inferred from tree-ring width of Pinus tabulaeformis in Helan Mountain. J. Geogr. Sci. 2007, 17, 293-303. [CrossRef]

24. Gao, J.; Yang, B.; He, M.; Shishov, V. Intra-annual stem radial increment patterns of Chinese pine, Helan Mountains, Northern Central China. Trees 2019, 33, 751-763. [CrossRef]

25. Wang, Y.J.; Ma, Y.Z.; Zheng, Y.H.; Lu, R.J.; Meng, H.W. Response of tree-ring width of Pinus tabulaeformis to climate factors in Luoshan Mountains of Ningxia. J. Desert Res. 2009, 29, 971-976.

26. Beguería, S.; Vicente-Serrano, S.M.; Reig, F.; Latorre, B. Standardized precipitation evapotranspiration index (SPEI) revisited: Parameter fitting, evapotranspiration models, tools, datasets and drought monitoring. J. Int. Climatol. 2014, 34, 3001-3023. [CrossRef]

27. Zhang, J.; Shen, Y.J. Spatio-temporal variations in extreme drought in China during 1961-2015. J. Geogr. Sci. 2019, 29, 67-83. [CrossRef]

28. Holmes, R.L. Computer-assisted quality control in tree-ring dating and measurement. Tree-Ring Bull. 1983, 43, 69-78.

29. Cook, E.R.; Holmes, R.L. Users Manual for Program ARSTAN; Laboratory of Tree-Ring Research, University of Arizona: Tucson, AZ, USA, 1986.

30. Wigley, T.M.; Briffa, K.R.; Jones, P.D. On the average value of correlated time series, with applications in dendro-climatology and hydrometeorology. J. Clim. Appl. Meteorol. 1984, 23, 201-213. [CrossRef]

31. Buras, A. A comment on the expressed population signal. Dendrochronologia 2017, 44, 130-132. [CrossRef]

32. Biondi, F.; Waikul, K. DENDROCLIM2002: A C++ program for statistical calibration of climate signals in tree-ring chronologies. Comput. Geosci. 2004, 30, 303-311. [CrossRef]

33. Groemping, U. Relative Importance for Linear Regression in R: The Package relaimpo. J. Stat. Softw. 2006, 17, 925-933.

34. Liu, Y.; Shi, J.; Shishov, V.; Vaganov, E.; Yang, Y.; Cai, Q.; Sun, J.; Wang, L.; Djanseitov, I. Reconstruction of May-July precipitation in the north Helan Mountain, Inner Mongolia since A.D. 1726 from tree-ring late-wood widths. Chin. Sci. Bull. 2004, 49, 405-409. [CrossRef]

35. Fang, K.; Peng, J.; Zhang, Y.; Tian, Q.; Chen, F.; Gou, X. A 1232-year tree-ring record of climate variability in the Qilian Mountains, northestern China. IAWA J. 2009, 30, 407-420.

36. Huang, J.; Deslauriers, A.; Rossi, S. Xylem formation can be modeled statistically as a function of primary growth and cambium activity. New Phytol. 2014, 203, 831-841. [CrossRef]

37. Li, M.-M.; Li, G. Relationship between phenology of vegetation canopy and phenology of tree cambium in Helan Mountains, China. J. Appl. Ecol. 2021, 32, 495-502.

38. Shi, J.F.; Liu, Y.; Cai, Q.F.; Yi, L. A case study of physiological characteristics of statistical correlation between Pinus tabulaeformis tree-ring widths and climatic factors. Acta Ecol. Sin. 2006, 26, 697-705.

39. Wu, Z.; Yu, L.; Du, Z.; Zhang, H.; Fan, X.; Lei, T. Recent changes in the drought of China from 1960 to 2014. Int. J. Clim. 2019, 40, 3281-3296. [CrossRef]

40. Richardson, S.; Dinwoodie, J. Studies on the physiology of xylem development. I. The effect of night temperature on tracheid size and wood density in conifers. J. Inst. Wood Sci. 1960, 6, 3-13.

41. Hosoo, Y.; Yoshida, M.; Imai, T.; Okuyama, T. Diurnal difference in the amount of immunogold-labeled glucomannans detected with field emission scanning electron microscopy at the innermost surface of developing secondary walls of differentiating conifer tracheids. Planta 2002, 215, 1006-1012. [CrossRef]

42. Liang, H.; Lyu, L.; Wahab, M. A 382-year reconstruction of August mean minimum temperature from tree-ring maximum latewood density on the southeastern Tibetan Plateau, China. Dendrochronologia 2016, 37, 1-8. [CrossRef]

43. Chen, F.; Yuan, Y.-J.; Wei, W.-S.; Yu, S.-L.; Zhang, T.-W.; Shang, H.-M.; Zhang, R.-B.; Qin, L.; Fan, Z.-A. Tree-ring recorded hydroclimatic change in Tienshan mountains during the past 500 years. Quat. Int. 2015, 358, 35-41. [CrossRef] 